\title{
Aplicación de un ciclo de mejora en el aula en la asignatura de Histología, en el Grado de Medicina
}

\section{Application of an improvement cycle in classroom in Histology subject, in the Degree of Medicine}

VICTORIA VÁZQUEZ ROMÁN

ORCID: https://orcid.org/0000-0002-7589-4251

Universidad de Sevilla

Departamento de Citología e

Histología Normal y Patológica

mvazquez2@us.es

Fecha de recepción: 01-06-2019

Fecha de aceptación: 12-06-2019

DOI: http://dx.doi.org/10.12795/9788447221912.022

Pp.: 521-540 


\section{Resumen}

Este artículo describe la aplicación de un Ciclo de Mejora en el Aula (CIMA) en la asignatura de Histología humana, que se imparte en el grado en Medicina. En concreto, el ciclo se centra en la docencia del tubo digestivo, que forma parte del bloque temático Aparato Digestivo, como parte de los contenidos de esta asignatura de formación básica de primer curso. Previo a la aplicación, se diseñó un mapa de contenidos que recogió, de forma jerarquizada y según niveles de profundidad, los contenidos estructurantes marcados como objetivos y se valoraron los conocimientos de los alumnos mediante un cuestionario inicial. El modelo metodológico aplicado fue de tipo mixto (con estrategias expositivas, investigativas y de aplicación práctica) y, para la ejecución del mismo, se programaron una serie de actividades que se desarrollaron durante un total de ocho horas. Una vez implementado el ciclo de mejora, se evaluaron los resultados usando como herramientas un cuestionario final y una encuesta de opinión. La experiencia docente fue muy constructiva para profesor y alumnos y los resultados fueron satisfactorios.

Palabras clave: Histología; Grado en Medicina; Docencia universitaria; Experimentación docente universitaria.

\section{Abstract}

This article describes the application of an Improvement Cycle in Classroom in Histology, in the degree of Medicine. Specifically, the cycle is focused on digestive tract teaching, which belongs to the thematic block of Digestive System, as part of the contents of this basic subject of first course. Previously to the application, a content map was designed that collected the critical contents marked as purposes hierarchically and according to depth levels. Student knowledge was evaluated by an initial questionnaire. The methodological method used was of a mixed type (with exposition, research and practical application strategies) and, for its execution, a series of activities were scheduled and developed for eight hours. Once the improvement cycle was implemented, the results were evaluated using a final questionnaire as a tool and an opinion poll. The teaching experience was very constructive for both teacher and students and the results were quite satisfactory.

Keywords: Histology; Degree in Medicine; University teaching; University teaching experimentation. 


\section{Contexto de la asignatura, planteamiento del tema y justificación del Ciclo de Mejora en el Aula}

Este Ciclo de Mejora en el Aula (CIMA) se ha desarrollado en la docencia de la asignatura Histología Humana. La asignatura se imparte en el segundo cuatrimestre del primer curso del Grado en Medicina y tiene como objetivos: adquirir habilidades para diagnosticar microscópicamente los cuatro tejidos básicos del organismo: epitelial, conjuntivo, muscular y nervioso; conocer y diagnosticar microscópicamente la organización estructural normal de todos los órganos y sistemas de nuestra anatomía. La Histología se define como la ciencia que estudia los tejidos, tanto desde el punto de vista estructural como funcional.

La metodología empleada en cada bloque temático parte de la explicación, de forma expositiva, de los conceptos teóricos. Posteriormente, se trabajan imágenes relacionadas con el tema en forma de seminarios, y una tercera parte del proceso de aprendizaje corresponde a la práctica, en la que, mediante el uso del microscopio, se revisan muestras reales de tejidos y órganos relacionados con el tema.

Para la aplicación de este ciclo de mejora se ha elegido el bloque temático "Estructura histológica del tubo digestivo", dentro del tema Sistema Digestivo.

El objetivo básico de este bloque temático es que el alumno conozca la morfología, estructura y función del tubo digestivo. Por su extensión no se ha considerado la cavidad oral. Según el proyecto docente de la asignatura los contenidos básicos son:

- Tubo digestivo. Estructura histológica general: capa mucosa, submucosa, muscular y serosa o adventicia.

- Esófago: Glándulas y transición muscular. 
- Estómago. Glándulas gástricas: variaciones regionales. Tipos celulares. Esfinter pilórico.

- Intestino delgado. Mecanismos de ampliación de superficie. Variaciones regionales. Tipos celulares.

- Intestino grueso. Apéndice vermiforme.

\section{Diseño previo del Ciclo de Mejora en el Aula}

\section{Evaluación de las ideas de los alumnos}

De un año a otro los alumnos cambian y, aunque el temario que se imparte en los programas de acceso a la universidad para Ciencias de la Salud suele ser similar, el conocimiento del alumnado no siempre es el mismo. Debido a esto, es necesario evaluar en forma de cuestionario inicial $(\mathrm{Cl})$ el grado de conocimientos que tienen sobre la materia a impartir.

La importancia del $\mathrm{Cl}$ radica en que, mediante su análisis previo, se pueden modificar, en caso de ser necesario, algunos aspectos de la práctica docente. Y de esta forma, antes de comenzar a impartirlos, se sabrán los obstáculos que se pueden encontrar y los puntos en los que es imprescindible incidir para favorecer el aprendizaje. En este caso concreto, el $\mathrm{Cl}$ está diseñado para indagar sobre los conocimientos que los alumnos tienen sobre la estructura histológica y funciones del tubo digestivo.

Las preguntas y resultados del $\mathrm{Cl}$ se analizarán más adelante en el apartado de análisis comparativo de los cuestionarios inicial (Cl) y final (CF), dentro de la evaluación del ciclo de mejora (véanse, más adelante, Figuras 3 a 6).

Jornadas de Formación e Innovación Docente del Profesorado | № 2 (2019) Esta obra se distribuye con la licencia Creative Commons Reconocimiento-NoComercial-SinObraDerivada 


\section{Mapa de contenidos}

Como se plantea en el capítulo "Los fines y los contenidos de enseñanza" del libro Enseñanza Universitaria (García Díaz, Porlán y Navarro, 2017), los contenidos son el centro del modelo didáctico y, para poder adaptar los contenidos a alumnos concretos en cada curso o clase, hay que tener dichos contenidos perfectamente estructurados. Antes de abordar el CIMA, se han priorizado los contenidos, y se han definido los conceptos estructurantes o imprescindibles, jerarquizando la información según niveles de profundidad.

Los contenidos seleccionados están representados en un mapa básicamente conceptual, en el que se han incluido también una breve relación de contenidos procedimentales y actitudinales (Figura 1). Los contenidos fundamentales contemplados son los siguientes:

- Contenidos conceptuales: Los contenidos conceptuales a su vez se dividen en conceptos morfológicos o estructurales y en conceptos funcionales:

- Conceptos morfológicos: Incluyen como eje central la estructura histológica común del tubo digestivo (azul en mapa de contenidos, Figura 1). Alrededor de este concepto central se ramifican y desarrollan el resto de contenidos, clasificados como estructura histológica particular de cada segmento del tubo digestivo. En el mapa de contenidos se representan en colores degradados según niveles de profundidad (esófago, celeste; estómago, rosa; intestino delgado, verde; intestino grueso, naranja).

- Conceptos funcionales (color gris en Figura.1): Corresponden a la función fisiológica atribuida a cada estructura. Ya sea una célula, una capa o un tipo de tejido.

- Contenidos procedimentales: En el mapa de contenidos se incluyen los contenidos procedimentales que corresponden a la metodología específica aplicada para fomentar destrezas concretas, que deben de adquirir 
los alumnos mediante la implementación del ciclo de mejora.

- Contenidos actitudinales: Son contenidos transversales en la formación del alumno, que le permitirán aplicarlos en cualquier asignatura o disciplina. Por lo tanto, le acompañarán ya para el resto de su formación como médico. 


\section{VICTORIA VÁZQUEZ ROMÁN}

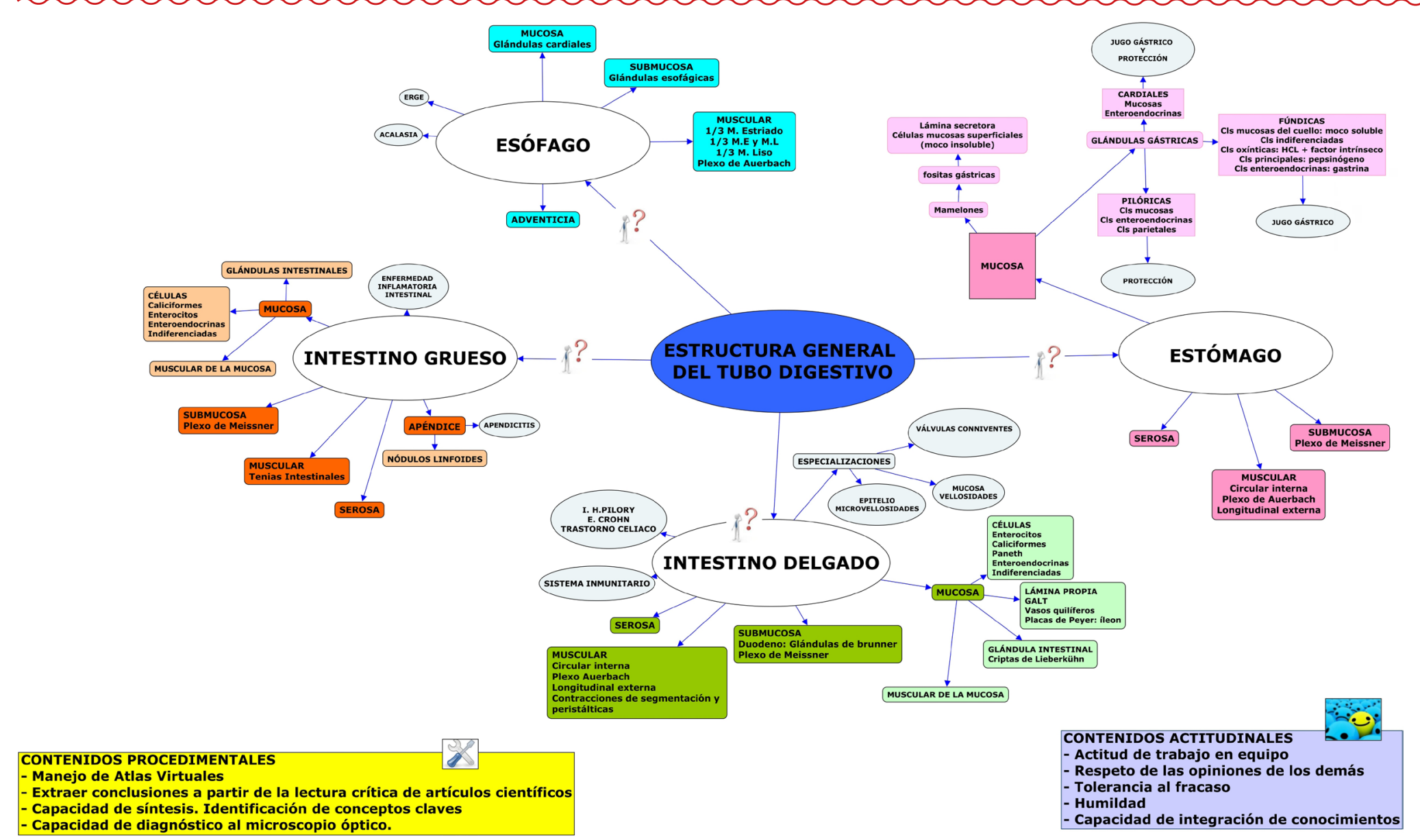

Figura 1. Mapa de contenidos.

Jornadas de Formación e Innovación Docente del Profesorado | № 2 (2019)

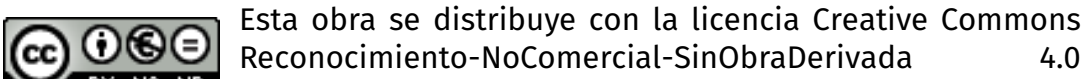

Internacional (CC BY-NC-ND 4.0.) 


\section{Modelo metodológico}

El modelo que se seguirá en este CIMA es de tipo mixto, contemplando tres tipos de estrategias: Investigativa + Expositiva + Aplicación Práctica. En el desarrollo del modelo juegan un papel importante las "preguntas estructurantes" que van encadenando la construcción del conocimiento (como puede verse en la secuencia de actividades). En efecto, el núcleo central y más importante, desde el punto de vista metodológico, está basado en una investigación. Mediante esta investigación el estudiante debe ser capaz de construir su propio conocimiento respecto a los conceptos morfológicos del tubo digestivo. La innovación consiste en que, hasta ahora, se explicaba la teoría de forma expositiva y después se relacionaba con las imágenes. En este caso se hará a la inversa. El propio alumno, por medio de la búsqueda y análisis de imágenes histológicas, será el encargado de inferir la organización histológica de cada segmento del tubo digestivo. Siguiendo el ejemplo del libro Dar clases con la boca cerrada (Finkel, 2008), los alumnos serán orientados mediante preguntas estructuradas y encadenadas, a las que tendrán que ir dando respuesta.

La segunda parte del conocimiento que será objeto de enseñanza es la que corresponde a los conceptos funcionales. La parte investigativa consistirá en la lectura crítica de documentos sobre las patologías más características de cada segmento del tubo digestivo, con la finalidad de que los alumnos relacionen el fallo en la función con la alteración estructural. Por otro lado, al terminar estas actividades investigativas, se realizará una explicación de los aspectos que no se hayan visto o que no estén del todo claros, a modo de resumen. Por último, en una clase práctica se aplicarán todos los conocimientos y habilidades adquiridas mediante la visualización microscópica de muestras relacionadas. 
En el diagrama de la Figura 2 se resume la metodología aplicada.

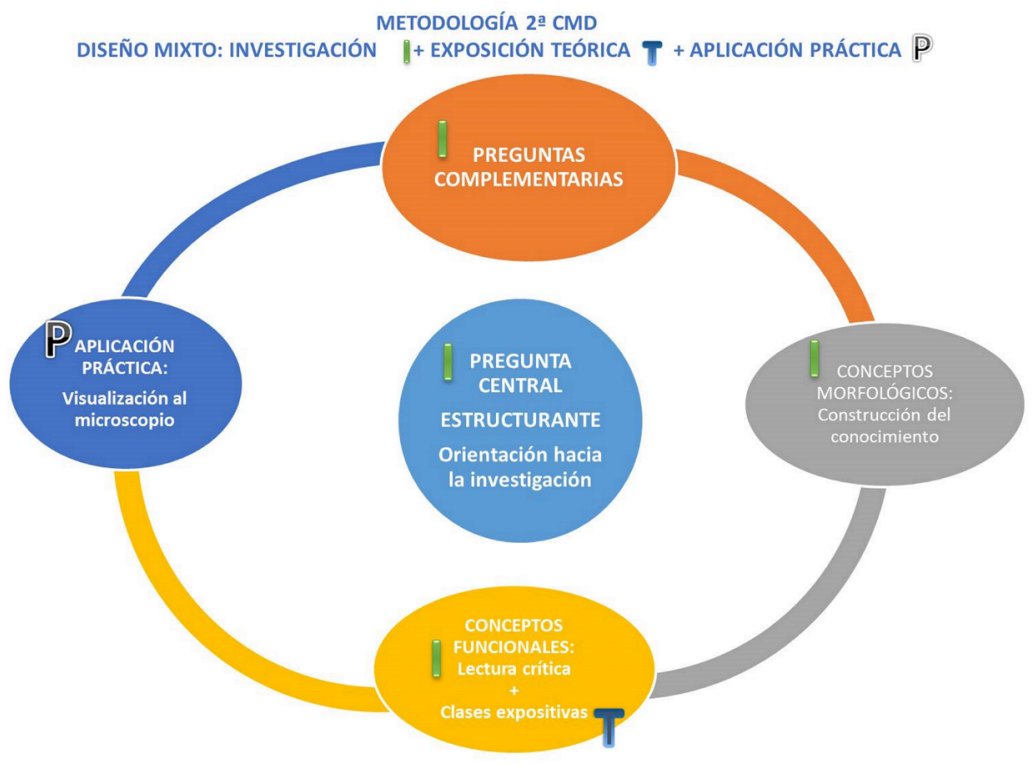

Figura 2. Modelo metodológico.

\section{Secuencia de actividades}

Este CIMA se desarrollará durante un total de 8 horas. Durante las 5 primeras horas se comenzará con una breve explicación sobre lo que se va hacer en esa hora, para que, posteriormente, el alumno trabaje de forma autónoma. Como es necesario el empleo de dispositivas, los estudiantes trabajarán en grupos. Una vez que hayan accedido a la información necesaria, se dedicará tiempo a explicar las dudas que surjan y a fijar conclusiones a modo de resumen. La última parte del ciclo se desarrollará en la sala de prácticas.

La secuencia de actividades (A) viene recogida de forma sintética en la Tabla 1.

Jornadas de Formación e Innovación Docente del Profesorado | № 2 (2019) Esta obra se distribuye con la licencia Creative Commons Reconocimiento-NoComercial-SinObraDerivada 
Tabla 1. Secuencia de actividades (A) del ciclo de mejora.

\begin{tabular}{|c|c|c|c|}
\hline \multicolumn{2}{|l|}{ AO } & \multicolumn{2}{|c|}{ PRESENTACIÓN DEL CIMA Y CUESTIONARIO INICIAL } \\
\hline \multirow{3}{*}{$\begin{array}{l}\text { A1 } \\
1 \\
\text { HORA }\end{array}$} & \multirow{3}{*}{ 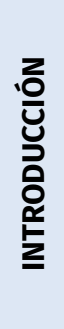 } & $\begin{array}{l}\text { PREGUNTA } \\
\text { ESTRUCTURANTE }\end{array}$ & $\begin{array}{l}\text { ¿Tiene todo el tubo digestivo una } \\
\text { estructura histológica común? }\end{array}$ \\
\hline & & $\begin{array}{l}\text { LECTURA CRÍ- } \\
\text { TICA DE TEXTOS } \\
\text { RELACIONADOS }\end{array}$ & Sistema digestivo \\
\hline & & $\begin{array}{l}\text { EXPLICACIÓN } \\
\text { TEÓRICA }\end{array}$ & Resumen y resolución de dudas \\
\hline \multirow{3}{*}{$\begin{array}{l}\text { A2 } \\
1 \\
\text { HORA }\end{array}$} & \multirow{3}{*}{ 온 } & $\begin{array}{l}\text { PREGUNTA } \\
\text { ESTRUCTURANTE }\end{array}$ & $\begin{array}{l}\text { Especialización morfológica: } \\
\text { ¿Hay glándulas en el esófago?, } \\
\text { ¿Cuál es la naturaleza secretora } \\
\text { de las mismas?; ¿En qué capa se } \\
\text { localizan? }\end{array}$ \\
\hline & & $\begin{array}{l}\text { LECTURA CRI- } \\
\text { TICA DE TEXTOS } \\
\text { RELACIONADOS }\end{array}$ & $\begin{array}{l}\text { Enfermedad por reflujo Gas- } \\
\text { tro-esofágico (ERGE) y Acalasia } \\
\text { Mecanismos de defensa de la mu- } \\
\text { cosa esofágica }\end{array}$ \\
\hline & & $\begin{array}{l}\text { EXPLICACIÓN } \\
\text { TEÓRICA }\end{array}$ & Resumen y resolución de dudas \\
\hline \multirow{3}{*}{$\begin{array}{l}\text { A3 } \\
1 \\
\text { HORA }\end{array}$} & \multirow{3}{*}{ 언 } & $\begin{array}{l}\text { PREGUNTA } \\
\text { ESTRUCTURANTE }\end{array}$ & $\begin{array}{l}\text { Especialización morfológica: } \\
\text { ¿Qué cambios estructurales ob- } \\
\text { servas entre el esófago y el } \\
\text { estómago? } \\
\text { ¿Cuáles son los tipos celulares } \\
\text { presentes en la mucosa gástrica? }\end{array}$ \\
\hline & & $\begin{array}{l}\text { LECTURA CRÍ- } \\
\text { TICA DE TEXTOS } \\
\text { RELACIONADOS }\end{array}$ & $\begin{array}{l}\text { Trastornos relacionados con la se- } \\
\text { creción ácida gástrica }\end{array}$ \\
\hline & & $\begin{array}{l}\text { EXPLICACIÓN } \\
\text { TEÓRICA }\end{array}$ & Resumen y resolución de dudas \\
\hline
\end{tabular}

Jornadas de Formación e Innovación Docente del Profesorado | № 2 (2019) Esta obra se distribuye con la licencia Creative Commons Reconocimiento-NoComercial-SinObraDerivada 4.0 Internacional (CC BY-NC-ND 4.0.) 


\begin{tabular}{|c|c|c|c|}
\hline \multirow{3}{*}{$\begin{array}{l}\text { A4 } \\
1 \\
\text { HORA }\end{array}$} & \multirow{3}{*}{ 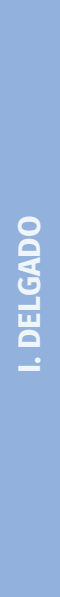 } & $\begin{array}{l}\text { PREGUNTA } \\
\text { ESTRUCTURANTE }\end{array}$ & $\begin{array}{l}\text { Especialización morfológica: } \\
\text { Tipos celulares que se encuentran } \\
\text { en la mucosa de las vellosidades } \\
\text { intestinales } \\
\text { Localización y función de las pla- } \\
\text { cas de Peyer. GALT } \\
\text { ¿Dónde se encuentran las glándu- } \\
\text { las de Brunner? }\end{array}$ \\
\hline & & $\begin{array}{l}\text { LECTURA CRITICA } \\
\text { DE TEXTOS } \\
\text { RELACIONADOS }\end{array}$ & $\begin{array}{l}\text { Infección por H. Pilory, Trastorno } \\
\text { Celiaco y enfermedad } \\
\text { de Crohn } \\
\text { Sistema inmunitario }\end{array}$ \\
\hline & & $\begin{array}{l}\text { EXPLICACIÓN } \\
\text { TEÓRICA }\end{array}$ & Resumen y resolución de dudas \\
\hline \multirow{3}{*}{$\begin{array}{l}\text { A5 } \\
1 \\
\text { HORA }\end{array}$} & \multirow{3}{*}{ 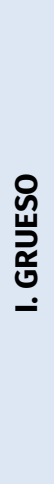 } & $\begin{array}{l}\text { PREGUNTA } \\
\text { ESTRUCTURANTE }\end{array}$ & $\begin{array}{l}\text { Tipos celulares que se encuentran } \\
\text { en la mucosa del I. grueso } \\
\text { ¿Qué son las Tenias intestinales? } \\
\text { ¿Hay tejido linfoide difuso en el } \\
\text { I. grueso? ¿Y nodular? ¿Y en el } \\
\text { apéndice? }\end{array}$ \\
\hline & & $\begin{array}{l}\text { LECTURA CRÍ- } \\
\text { TICA DE TEXTOS } \\
\text { RELACIONADOS }\end{array}$ & $\begin{array}{l}\text { Enfermedad inflamatoria } \\
\text { intestinal } \\
\text { Apendicitis }\end{array}$ \\
\hline & & $\begin{array}{l}\text { EXPLICACIÓN } \\
\text { TEÓRICA }\end{array}$ & Resumen y resolución de dudas \\
\hline \multirow{3}{*}{$\begin{array}{l}\text { A6 } \\
2 \text { HO- } \\
\text { RAS Y } \\
30 \text { MI- } \\
\text { NUTOS }\end{array}$} & \multirow{3}{*}{ S } & INDIVIDUAL & $\begin{array}{l}\text { Visualización al microscopio óp- } \\
\text { tico de cortes histológicos de cada } \\
\text { segmento del tubo digestivo }\end{array}$ \\
\hline & & EN GRUPO & $\begin{array}{l}\text { Elaboración de mapas conceptua- } \\
\text { les con imágenes histológicas to- } \\
\text { madas por los alumnos }\end{array}$ \\
\hline & & GRUPO COMPLETO & $\begin{array}{l}\text { Exposición y comentario de los } \\
\text { mapas }\end{array}$ \\
\hline AF & \multicolumn{3}{|c|}{ CUESTIONARIO FINAL Y EVALUACIÓN DEL CIMA } \\
\hline
\end{tabular}

Jornadas de Formación e Innovación Docente del Profesorado | № 2 (2019) Esta obra se distribuye con la licencia Creative Commons Reconocimiento-NoComercial-SinObraDerivada 4.0 Internacional (CC BY-NC-ND 4.0.) 


\section{Cuestionario final}

Para evaluar el aprendizaje del alumnado, tras la aplicación de las actividades correspondientes al CIMA, se les pasará un cuestionario final (CF). La finalidad es disponer de una herramienta que permita evaluar si el alumno ha adquirido los conocimientos que se habían marcado como objetivo. Igual que en el $\mathrm{Cl}$, no se pretende hacer un examen sobre conceptos sino evaluar el aprendizaje desde un punto de vista cualitativo.

Las preguntas del CF indagan sobre los mismos aspectos que las del $\mathrm{Cl}$, pero en este la mayoría son preguntas abiertas, que permiten comprobar si realmente la respuesta es correcta. Para clasificar las respuestas se establecen cuatro niveles, según los siguientes criterios:

Nivel 1: No responde o la respuesta es errónea.

Nivel 2: Respuesta correcta pero demasiado general. No comenta la especificidad de la zona o no justifica la respuesta.

Nivel 3: Respuesta correcta, especifica claramente la función del segmento o diagnostica sobre una imagen, pero no lo relaciona con ninguna estructura histológica concreta.

Nivel 4: Respuesta correcta, especifica claramente la función del segmento o diagnostica la imagen, y relaciona la función con la estructura histológica que la desarrolla.

Las preguntas y resultados del CF se muestran en el apartado de evaluación del CIMA y se comparan con las del $\mathrm{Cl}$ (Figura 3 a 6). Lo resultados se representan en forma de escalera de aprendizaje, que permite el análisis comparativo de la evolución de los alumnos de manera visual (Rivero y Porlán, 2017). 


\section{Aplicación del Ciclo de Mejora en el Aula}

\section{Informe sobre el desarrollo de las actividades}

Como se ha expuesto anteriormente, la primera actividad realizada ha sido el $\mathrm{Cl}$. La primera parte de cada clase es la que siguió una estrategia investigativa, a los alumnos se les facilitó una relación de atlas virtuales en los que buscaron información para construir su propio conocimiento sobre la estructura histológica del tubo digestivo. Al principio, esta actividad les resultó un poco complicada, porque no están habituados a tener que extraer información de imágenes sin una base teórica previa. Esto hizo que, en los primeros días, esta actividad consumiera más tiempo del programado.

Algunos de los atlas empleados incluian textos explicativos que facilitaban la construcción de la estructura histológica y tipos celulares. Una vez que entendieron la metodología, esta actividad comenzó a ser más productiva y les resultó entretenida y útil. Las páginas más visitadas fueron la del atlas del departamento (https://citologiaehistologia.es/histologiavirtual/) y la de la Universidad de Vigo (https://mmegias.webs.uvigo.es/), que además incluye un microscopio virtual que les gustó mucho.

La segunda actividad que se realizó fue la lectura crítica de documentos sobre las patologías más frecuentes de cada zona. La mayoría fueron artículos publicados en revistas médicas y de difusión sanitaria. Al ser patologías comunes, en esta actividad pusieron bastante interés. De todas formas, no analizamos la patología en sí; tan sólo los aspectos estructurales que están implicados en cada una de ellas para, de esta forma, extraer información sobre la función atribuida a cada segmento. En esta parte de las clases fue donde realmente los estudiantes comenzaron a 
integrar conceptos y resultó ser una actividad muy útil. En ambas actividades los alumnos trajeron sus ordenadores y trabajaron tanto individualmente como en grupos; de hecho, cada día se fueron animando más a trabajar en grupo y se creó un clima de debate entre ellos.

La última actividad diaria era una presentación por parte de la profesora, a modo de resumen, sobre lo tratado en la clase. Es importante que queden fijados los conceptos estructurantes y asegurar que todos los alumnos los han entendido.

Como está recogido en la secuencia de actividades (Tabla 1), se realizó una sesión práctica en la sala de prácticas del Departamento. Una vez realizado el control de la asistencia y después de que cada alumno se ajustó su microscopio, se les repartió una muestra de cada segmento.

Las muestras no estaban marcadas como otras veces, por lo que, durante este tiempo y sólo con la observación microscópica, los alumnos debían de identificar a qué zona correspondía cada muestra, y se les permitió el uso de libros, apuntes y dispositivas para consultar información.

En la segunda parte de la práctica trabajaron en grupos. A cada grupo se le asignó un segmento del tubo digestivo y tuvieron que realizar un mapa conceptual del segmento basado en imágenes que ellos mismos capturaban de los microscopios. Esta actividad, sorprendentemente, fue la que menos les gustó. Posiblemente porque demandaba una actitud más participativa por su parte, y no están acostumbrados a ello.

Para la puesta en común de los trabajos realizados, una vez que los enviaron por medio de la plataforma de enseñanza virtual, se seleccionaron uno por zona para que no fuera muy repetitivo.

El CF se realizó al final de la práctica. 


\section{Evaluación del aprendizaje de los alumnos: comparación entre los cuestionarios inicial y final}

Tanto el Cl como el CF han constado de 4 preguntas y ambos han sido contestados por 42 alumnos. Las preguntas del $\mathrm{Cl}$ tenían como finalidad indagar sobre las competencias del alumno antes de impartir los conocimientos de los temas del CIMA, por lo que se planteó como una autoevaluación. Se les pidió que valoraran su nivel de conocimientos respecto a la estructura histológica del tubo digestivo y sobre las funciones de cada segmento, su capacidad para diferenciar al microscopio una muestra de estómago de una de intestino delgado y, por último, se les preguntaba si se veían capaces de relacionar cada especialización histológica con la función atribuida.

Para el CF se han modificado algunas preguntas, aunque van encaminadas a responder en el mismo sentido que las del $\mathrm{Cl}$, pero con la intención no de autoevaluación sino de comprobar lo aprendido. En el CF la mayoría han sido preguntas abiertas. La primera pregunta fue la misma. Para la segunda, esta vez, se les pidió que redactaran brevemente la función de una zona concreta. La tercera pregunta consistió en diferenciar sobre una imagen histológica si la muestra que veían era de estómago o de intestino delgado. En la última pregunta debían de decir qué características histológicas de la mucosa gástrica permiten que se realice la digestión y a su vez que ésta no resulte dañada.

Pese a que el enfoque de ambos cuestionarios ha sido distinto, su comparación permite valorar el posible progreso en el aprendizaje. En las Figuras 3 a 6, los resultados se expresan, para cada pregunta, tanto en forma de gráfico de barras como en escalera de aprendizaje. En las escaleras se muestran los porcentajes de alumnos por peldaño. 

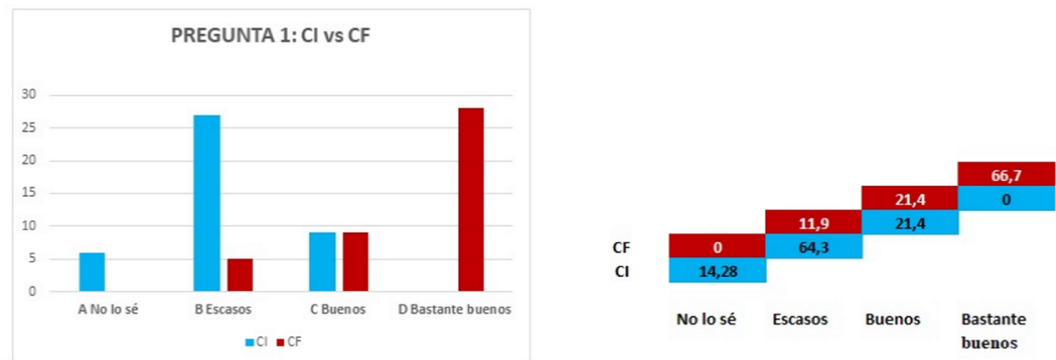

Figura 3. Comparación entre Cl y CF. Pregunta 1: Evaluación sobre los conocimientos de la estructura histológica del tubo digestivo.
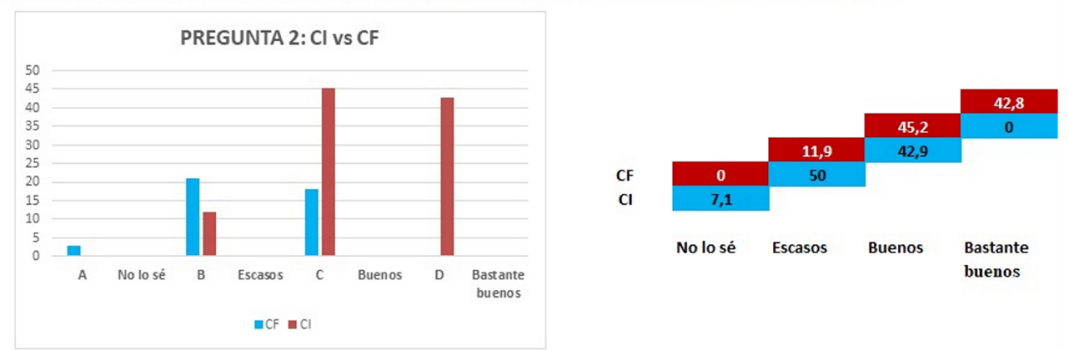

Figura 4. Comparación entre Cl y CF. Pregunta 2: Nivel de conocimiento sobre las funciones del tubo digestivo.
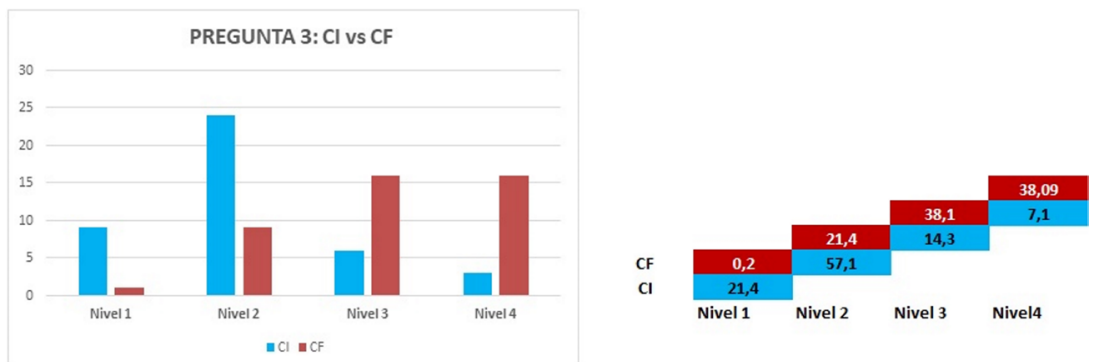

Figura 5_Comparación entre Cl y CF. Pregunta 3.jpg
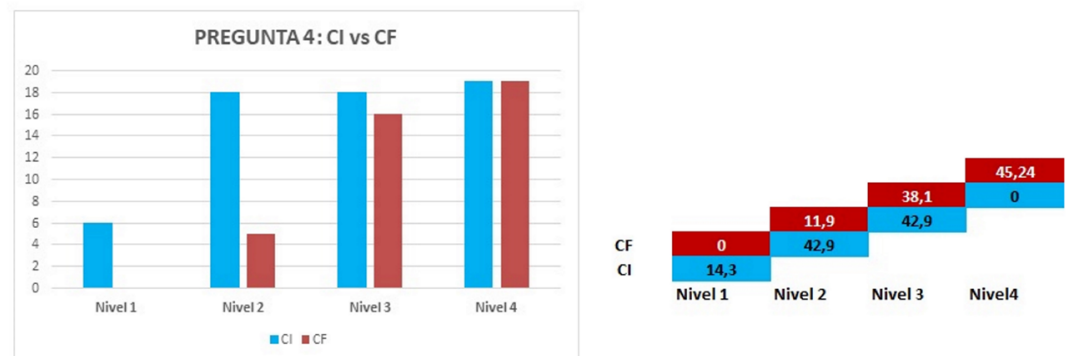

Figura 6. Comparación entre Cl y CF. Pregunta 4: Especialización histológica de la mucosa gástrica.

Jornadas de Formación e Innovación Docente del Profesorado | № 2 (2019) Esta obra se distribuye con la licencia Creative Commons Reconocimiento-NoComercial-SinObraDerivada 
Como se puede ver en los gráficos de cada pregunta, el nivel alcanzado por los alumnos es bastante alto. En casi todas, el mayor porcentaje de alumnos se encuentra entre los niveles 3 y 4 .

Una de las preguntas en las que la evolución no ha sido tan buena es la pregunta 4. En esta pregunta inicialmente se les preguntó si se veían con conocimientos como para relacionar la estructura histológica con la función de un segmento del tubo digestivo. Posiblemente en el $\mathrm{Cl}$ los alumnos se valoraron por encima de la realidad y en el final, donde han tenido que ponerlo en práctica, el resultado se ajusta más a la realidad.

\section{Evaluación del Ciclo de Mejora en el Aula}

Para evaluar el CIMA se les pidió al alumnado que contestaran desde casa y mediante OPINA una encuesta sencilla y breve. En general, la valoración de la aplicación del ciclo de mejora es buena, y los resultados son satisfactorios. Los alumnos expresan que han aprendido más que con las clases tradicionales, que las actividades propuestas les han resultado interesantes, e incluso que les gustaría que la innovación se aplicara en otra parte del temario.

La aplicación de esta actividad de mejora docente, ha sido una experiencia muy enriquecedora, después de comprobar que los alumnos han aprendido y alcanzado todos los conceptos que se habían marcado como objetivos. Creo que los alumnos están abiertos a este tipo de actividades y pueden asumir un modelo didáctico con enfoque investigativo.

Aunque este CIMA se he llevado a cabo durante 8 horas de docencia, es necesario invertir muchas horas de trabajo antes de su aplicación, por lo que se debe de informar a los alumnos de que en los ciclos de mejora todas 
las actividades están pensadas y programadas y que no se improvisan. Aun así, en las clases expositivas está todo más controlado, sobre todo los tiempos, por eso es fundamental tener muy estructurados los contenidos (García Díaz, Porlán y Navarro, 2017).

La aplicación de actividades de mejora, aun siendo necesarias, se debería de ir realizando de forma gradual, a lo largo del temario ya que exigen mucha preparación y responsabilidad. En la práctica habitual, los docentes, en algún momento, hacemos alguna actividad que se sale de la clase puramente expositiva, pero, generalmente, los principios que han guiado la práctica docente se pueden calificar como clásicos o transmisivos. El profesor tiene libertad para salirse del guion establecido como habitual y cada profesor o profesora debe construir su propio modelo didáctico (García Pérez y Porlán, 2017). Creo que el modelo didáctico ideal sería aquel que lograse mantener al alumno implicado y motivado y, sobre todo, aquel en el que el aprendizaje del alumno fuera real y que posibilitara la aplicación de conocimientos fuera del aula; lo ideal sería que el alumno pueda vivir experiencias intelectuales completas, aplicables y duraderas (Bain, 2007; Delval, 2000).

El modelo metodológico que, a día de hoy, me parece posible llevar a cabo, es un modelo mixto, que utilizara varias estrategias de enseñanza, con actividades variadas. Las clases expositivas no son suficientes, pero tampoco hay que desterrarlas, creo que son la forma más útil de asentar conocimientos. Ahora bien, también creo que habría que combinarlas con otras actividades en las que el docente no sea el actor central, sino que ceda protagonismo al alumno. Y esto sólo es posible diseñando una serie de actividades que dirijan a los alumnos hacia la adquisición de conocimientos y habilidades relacionadas con el temario (De Alba y Porlán, 2017; Finkel, 2008). 
En cada asignatura de cada curso y de cada grado no sólo los alumnos son evaluados, sino que nosotros los profesores y profesoras debemos de asumir nuestra responsabilidad y diariamente revisar la evolución de las clases y hacer las mejoras necesarias. En este sentido el diario del profesor resulta ser una herramienta fundamental (Porlán y Martín, 1991).

En todo caso, no debemos de olvidar el entorno en el que se desarrolla cada clase con sus limitaciones y obstáculos para el aprendizaje, como son el número de alumnos, los espacios, los horarios... Pero, en cualquier caso, hay un amplio margen de mejora al que no podemos dar la espalda.

Como conclusión, me planteo una docencia centrada en el alumno, innovadora pero que fije claramente los conceptos a transmitir, en la que se compruebe que los alumnos están llegando a los objetivos, y que, en caso contrario, se puedan reformular las actividades para llegar al menos a asegurar los conceptos fijados como estructurantes en cada caso concreto.

Profesores preparados, alumnos motivados y compromiso por ambas partes para llegar a adquirir habilidades y procesos mentales que preparen al alumno para ser competentes en su futura profesión y tener una actitud crítica en cada disciplina.

Jornadas de Formación e Innovación Docente del Profesorado I № 2 (2019) Esta obra se distribuye con la licencia Creative Commons 


\section{Referencias bibliográficas}

Bain, K. (2007). Lo que hacen los mejores profesores universitarios. Valencia: Publicacions de la Universitat de València.

De Alba, N. y Porlán, R. (2017). La metodología de enseñanza. En R. Porlán (Coord.), Enseñanza Universitaria. Cómo mejorarla (pp. 37-54). Madrid: Morata.

Delval, J. (2000). Aprender en la vida y en la escuela. Madrid: Morata.

Finkel, D. (2008): Dar clase con la boca cerrada. Valencia: Publicacions de la Universitat de València.

García Díaz, J. E., Porlán, R. y Navarro, E. (2017). Los fines y los contenidos de enseñanza. En R. Porlán (coord.), Enseñanza Universitaria. Cómo mejorarla (pp. 55-72). Madrid: Morata.

García Pérez, F. F. y Porlán, R. (2017). Los Principios Didácticos y el Modelo Didáctico Personal. En R. Porlán (coord.), Enseñanza Universitaria. Cómo mejorarla (pp. 93-104). Madrid: Morata.

Porlán, R. y Martín, J. (1991). El diario del profesor. Un recurso para la investigación en el aula. Sevilla: Díada.

Rivero, A. y Porlán, R. (2017). La evaluación de la enseñanza universitaria. En R. Porlán (coord.), Enseñanza Universitaria. Cómo mejorarla (pp. 73-92). Madrid: Morata.

Jornadas de Formación e Innovación Docente del Profesorado | № 2 (2019) Esta obra se distribuye con la licencia Creative Commons Reconocimiento-NoComercial-SinObraDerivada 4.0 Internacional (CC BY-NC-ND 4.0.) 